\title{
Wilton H. Bunch (January 12, 1935-May 16, 2021)
}

\author{
Michael R. Zindrick ${ }^{1,2,3}$
}

Published online: 5 July 2021

(c) Scoliosis Research Society 2021

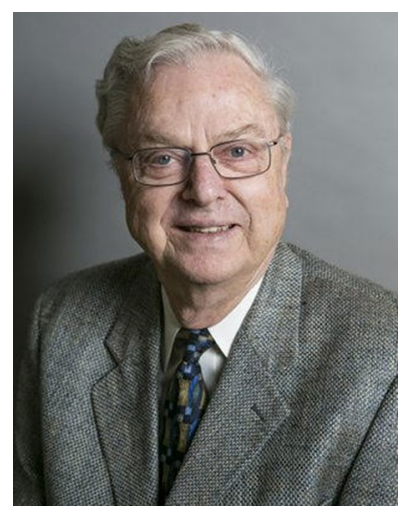

The academic world lost an outstanding teacher with the passing of Wilton H. Bunch on May 16, 2021. Wilton was an active member of the SRS, joining in 1971. He served on the Board of Directors (1973-1980), as Treasurer (1976-1980), and as the 17th President of the SRS (1985-1986).

Raised in College Place, Washington, Wilton attended Walla Walla College majoring in Mathematics and graduating in 1956. He received his MD from Loma Linda University in 1960. After interning at Loma Linda, he served in the US. Public Health Service, Department of Indian Health, The Crow Agency in Montana from 1961 to 1963. He attained a PhD in Physiology from 1967 and completed his Orthopedic Residency in 1968 at University of Minnesota where he trained under John Moe. From 1969 to 1975 he was the Donald Barnes Professor of Orthopedics at the University of Virginia in Charlottesville and became the Dr. William M. Scholl Professor and founding Chairman of Orthopedics and Rehabilitation Loyola University of Chicago where he served from 1975 to 1985. While at Loyola

Michael R. Zindrick

zindrickmike@cs.com

1 Hinsdale Orhthopaedics, Hinsdale, IL, USA

2 Orthopaedic Surgery, Loyola University, Chicago, IL, USA

3 Neighborhood Clinic, Naples, FL, USA

he founded and was the first Director of the Rehabilitation Research and Development Center housing rehabilitation research laboratories in Biomechanics, Neuro Research and Vision Research for the Blind at Hines Veterans Hospital. He served as a Secretary-Treasurer of the Academic Orthopedic Association 1981-1984 and President 1984-1985. He was an active member in the AAOS and served as Chairman of the Committee and Prosthetics and Orthotics 1981-1985. He was an examiner for the American Board of Orthopedic Surgeons from 1976 to 1989 where he was actively involved in question preparation for the oral examinations. He served on the Committee on Faculty Practice Plans and Dean's Letter for The Association of American Medical Colleges, as a Representative for the Counsel of Academic Societies and Counsel of Deans. He was active in the Illinois Division of Services for Crippled Children's and served on the advisory board from 1978 to 1988 . He was an active member in The Association of Orthopedic Chairman, Pediatric Orthopedic Society, Association of Bone and Joint Surgery, American College of Surgeons, Orthopedic Research Society, American Physiological Society, Society for Christian Ethics, American Society for Bioethics and Humanities and Society for Practical and Professional Ethics.

Ever the student, Wilton obtained an MBA the University of Chicago in 1983 and set his sights on higher academic goals. In 1985 he became to Dean for Medical Affairs and Professor of Surgery (Orthopedics) at the University of Chicago. From 1988 to 1990 he served as the Dean, College of Medicine, University of South Florida.

In the 1990's Wilton, the life-time student, pursued additional areas of interest. He became an Ordained Episcopalian Priest in 1997 and obtained a Master of Divinity from the Church Divinity School of the Pacific in 1998. From 2000 to 2017 he was back pursuing his passion, teaching as Professor of Ethics, Beeson Divinity School in Sampson University Birmingham, Alabama. He worked as an Assistant Priest in the Episcopal Church, Birmingham Alabama from 2001 to 2021.

He served on the editorial boards of the Journal of Bone and Joint Surgery, Clinical Orthopedics and Related 
Research, Journal of American Medical Association, Journal of Pediatric Orthopedics, Spine and Journal of Society for Christian Ethics. He was an Ethics consultant to the North American Spine Society. During his career he authored 118 peer reviewed articles, wrote 28 book chapters, published 8 books and performed 32 Visiting Professorships. He was honored in 2006 with the establishment of the Wilton $\mathrm{H}$. Bunch Interdisciplinary Faculty Fellowship at Samford University and the Wilton Bunch Lecture in Medical Ethics in Orthopaedic Surgery at Loyola in 2012.

When not teaching or writing Wilton found time to coach the Stanford University Ethics Bowl Team and play the double bass in the Stanford University Orchestra. He was a passionate gardener and student of genealogy, publishing 3 books on his genealogical research.
He is survived by his wife of 38 years Victoria Dvonch, $\mathrm{MD}$, son Brett, grandchildren Owen and Charlotte. He was proceeded in death by son Wesley and daughter Brenda.

During his career Wilton had many titles, pediatric orthopedic surgeon, chairman, dean, colleague, mentor, husband, father and friend. The title he most cherished and will be best remembered is that of teacher. Wilton taught problem solving and critical thinking. He had a gift of inspiring college students, graduate students, medical students and residents to strive to reach their maximum potential. He will be greatly missed.

Fond memories and condolences for the family may be left at: https://www.dignitymemorial.com/obituaries/homew ood-al/wilton-bunch-10196414 